ENCYCLOPEDDIE Encyclopédie berbère

BERBERE

10 | 1991

10 | Beni Isguen - Bouzeis

\title{
Bida (Djemma Saharidj)
}

E.B.

\section{OpenEdition}

Journals

Édition électronique

URL : http://journals.openedition.org/encyclopedieberbere/1745

DOI : 10.4000/encyclopedieberbere. 1745

ISSN : 2262-7197

\section{Éditeur}

Peeters Publishers

\section{Édition imprimée}

Date de publication : 1 décembre 1991

Pagination : 1492

ISBN : 2-85744-549-0

ISSN : 1015-7344

\section{Référence électronique}

E.B., « Bida (Djemma Saharidj) », Encyclopédie berbère [En ligne], 10 | 1991, document B74, mis en ligne le 01 mars 2013, consulté le 25 septembre 2020. URL : http://journals.openedition.org/ encyclopedieberbere/1745; DOI : https://doi.org/10.4000/encyclopedieberbere.1745

Ce document a été généré automatiquement le 25 septembre 2020

(C) Tous droits réservés 


\section{Bida (Djemma Saharidj)}

E.B.

1 Ville antique actuellement occupée par la petite cité kabyle de Djemmaa Saharidj dans la haute vallée du Sébaou. Le municipe de Bida est cité par Ptolémée, il figure sur la Table de Peutinger et dans l'Itinéraire d'Antonin sous la forme fautive de Bidil, il est situé entre Rusuccuru (Dellys) et Saldae (Bougie / Béjaïa), à 40 milles à l'ouest de Tubusuptu (Tiklat) et à 27 milles à l'est de Tigisi (Taourga). Curieusement, cette ville qui n'a joué aucun rôle important est encore souvent citée dans l'Antiquité tardive par l'Anonyme de Ravenne, le Cosmogrape d'Aethicus, Julius Honorius. La Notitia dignitatum, il est vrai révèle l'existence d'un praepositus limites Bidensis et du même coup l'importance régionale de la cité, dont un évêque, Campanus, est cité dans la Notitia de 484.

2 Les ruines, reconnues dès le milieu du siècle dernier, n'ont jamais fait l'objet de fouilles régulières, d'où l'imprécision des descriptions. Les vestiges s'étendent sur 20 ha; on y reconnaît des thermes et l'affleurement de nombreux murs. D'après C. Vigneral, la ville semble enterrée sous $2 \mathrm{~m}$ de sédiments sinon plus. Elle occupait une croupe dominant la haute vallée du Sébaou et, fait exceptionnel en Maurétanie, elle ne semble pas avoir été pourvue d'une enceinte. Il existe toutefois à quelque distance et à $200 \mathrm{~m}$ plus haut, un petit camp dont le mur d'enceinte, épais de 0,60 m seulement, épouse la forme du piton sur lequel il a été construit. Un réduit de $7 \mathrm{~m}$ sur $5 \mathrm{~m}$ en occupe le centre. La nécropole s'étendait à l'ouest de l'agglomération antique; il y fut reconnu des tombeaux maçonnés.

3 L'épigraphie, assez misérable, a donné un document rare (Libyca, 1959, p. 101) mentionnant la cérémonie de «l'enterrement de la foudre » (Fulgur conditu) de façon à la rendre inoffensive tout en enrichissant le sol. Parmi les inscriptions funéraires, on retiendra la mention de l'ethnonyme Nababi (Libyca, 1955, p. 373) qui renvoie aux Nababes/Nabades, peuple de Maurétanie césarienne cité par Pline l'Ancien (V, 2, 21). Deux autres inscriptions de Kabylie, du Castellum Tulei, mentionnent également ce nom (C.I.L., VIII, 9006 et Rec. des not. et Mém. de la Soc. archéol. de Constantine, 1911, p. 307). 


\section{BIBLIOGRAPHIE}

Vigneral C. de, Ruines romaines d'Algérie. Kabylie du Djurdjura, 1868, pp. 48-57.

Gsell S., Atlas archéologique de l'Algérie, feuille $\mathrm{n}^{\circ}$ 6, Fort-National, $\mathrm{n}^{\circ} 104$.

Leglay M., « Fulgur conditu. Un lieu consacré par la foudre en Grande Kabylie », Libyca, t. VII, 1959, pp. 101-109.

Martin J., Bida municipium en Maurétanie césarienne (Djemaa Saharidj), Fichier de documentation berbère, Fort-National, 1969.

INDEX

Mots-clés : Algérie, Antiquité, Villes 